\title{
La conformación de la Cámara de los Comunes y los gobiernos de Canadá a través de cinco procesos electorales federales (2000-2011) Segunda parte*
}

\author{
Oliver Santín Peña ${ }^{* *}$
}

\section{RESUMEN}

Este trabajo muestra la evolución reciente que ha experimentado el escenario político canadiense de 2000 a 2011, toda vez que durante ese periodo se ha transitado de un gobierno de mayoría absoluta liberal, con Jean Chrétien a la cabeza, a otro de mayoría conservadora con Stephen Harper como primer ministro. Este cambio ha sido producto de intensas batallas político-electorales, las cuales han requerido del voto ciudadano en cinco ocasiones, durante un periodo de once años, lo que implica un llamado electoral federal prácticamente cada dos años, situación que manifiesta el intenso activismo partidista que se ha desarrollado en el país durante la década pasada.

Palabras clave: Canadá, política, elecciones, Cámara de los Comunes.

\section{ABSTRACT}

This article traces the recent evolution of Canadian politics, from 2000 to 2011. During this period, the country has transitioned from a Liberal government with an absolute majority, headed by Jean Chrétien, to a majority Conservative government headed by Stephen Harper. This change has been the product of intense political-electoral battles that have required that the citizenry go to the polls 5 times in 11 years. This reflects the intense partisan activism that has taken place there in the last decade.

Key words: Canada, politics, elections, House of Commons.

\footnotetext{
* Debido a su extensión original, el presente artículo se dividió. Ésta es la segunda de dos entregas. La primera se publicó en Norteamérica. Revista Académica, año 7, no. 2 (julio-diciembre de 2012).

** Investigador del Área de Estudios de la Globalidad, CISAN, UNAM, oliversantin@hotmail.com.
} 


\section{INTRODUCCIÓN}

Tal y como se señaló en la primera parte de este artículo, el inicio del siglo XXI en Canadá se caracterizó por experimentar una intensa dinámica política, la cual ha fortalecido al partido de la derecha canadiense (Partido Conservador) en el poder, cuyo líder y primer ministro, Stephen Harper, ha consolidado su presencia con un gobierno de mayoría. Lo anterior sucedió al mismo tiempo en que el Partido Neodemócrata, el de la izquierda nacional, se ubicó -inéditamente- como la primera minoría parlamentaria.

Esta situación ha ubicado (y relegado) en una lejana tercera posición al otrora poderoso Partido Liberal, mientras que el Bloque Quebequense ha reducido su presencia a una mínima expresión numérica en la Cámara de los Comunes de Canadá. Estas condiciones ofrecen nuevos escenarios políticos en la dinámica parlamentaria del país, que ayudan a entender el funcionamiento y estabilidad del sistema político canadiense en el siglo XXI. Asimismo, se observa cómo el sistema experimenta nuevas dinámicas desde el poder, estimulando posicionamientos y estrategias partidistas que buscan adaptarse a toda costa a las novedosas situaciones imperantes.

En este sentido, conviene señalar que la XLI Legislatura canadiense es resultado de esta nueva y activa dinámica, que, en buena medida, reconfigura el imaginario colectivo de los electores canadienses, cuya volatilidad electoral ha generado escenarios políticos cada vez más polarizados entre la derecha en el poder y la izquierda como principal opositora. Cabe señalar que esta característica no tiene precedentes en la historia política de Canadá, donde liberales y conservadores solían alternarse el poder, en tanto que la oposición, con discursos divergentes, demanda acciones gubernamentales coincidentes.

Esto último ha obedecido a la existencia de un consenso pragmático entre las elites liberales y conservadoras, pues juntas han logrado asentar, a lo largo de décadas, una muy efectiva fórmula para monopolizar el ejercicio del poder, lo que ha sido posible gracias a acciones de gobierno poco divergentes en los hechos, condición que permite la continuidad de proyectos y programas de desarrollo sustentable, más allá del partido en el poder. Así, con estos elementos se entenderá que la posición conservadora de las elites del Partido Liberal -en el sentido de rechazar alianzas trascendentes con la izquierda neodemócrata canadiense, después de las elecciones federales de 2008- habría significado comprometer los acuerdos alcanzados tradicionalmente con la cúpula del Partido Conservador.

Por otra parte, en las elites del Partido Conservador también ha existido, durante mucho tiempo, la tendencia a mantener alejada de la toma de decisiones a la extrema derecha del partido. Esta situación facilitaba las coincidencias con las elites liberales. 
Empero, todo parece indicar que en el siglo xxI se ha ido rompiendo este delicado equilibrio entre las cúpulas de ambos partidos, una vez que los grupos más tradicionalistas y ortodoxos del Partido Conservador se consolidaron en el poder, diseñando una estrategia tendiente a la destrucción política de sus opositores liberales; esta situación provocó el ascenso de una izquierda neodemócrata (en teoría más contestataria y menos dócil) como primera minoría parlamentaria.

\section{LA ELECCIÓN DE 2008: ENTRE EL DILEMA ECOLÓGICO Y UNA POLÉMICA PRÓRROGA PARLAMENTARIA}

Las elecciones de enero de 2006 permitieron que el Partido Conservador, encabezado por su líder Stephen Harper, regresara al poder en Canadá, terminando así con una ausencia tory que se prolongó desde 1993, justo cuando Brian Mulroney concluyó su segundo mandato como primer ministro. Una vez que fue oficial la toma de protesta de Harper, el nuevo gobierno conservador implementó, desde el inicio, una serie de medidas tendientes a fortalecer su presencia como primera minoría en el poder. Una de estas primeras acciones fue reducir de cinco a cuatro años el periodo para convocar a nuevas elecciones, desde una posición de gobierno mayoritario; esto en clara alusión a la práctica común del liberal Jean Chrétien, quien en su intento por diezmar a la oposición llegó a adelantar elecciones federales en dos ocasiones (1997 y 2000). Esta misma propuesta, sin embargo, no impedía que una mayoría opositora convocara a elecciones adelantadas, cuando así se decidiera por consenso de sus líderes.

$\mathrm{Al}$ mismo tiempo, y considerando los resultados de la segunda parte de la Comisión Gomery, que se dio a conocer a la opinión pública en febrero de 2006, el nuevo gobierno conservador creó mecanismos que transparentaron el uso de los recursos. Esto mediante el Acta de Responsabilidad Federal (Federal Accountability Act). Paralelamente, tal y como Harper había prometido en campaña, su administración propuso a la Cámara de los Comunes una reducción del impuesto de bienes y servicios (Good and Services Tax, GST), de modo que, aprovechando la popularidad alcanzada por el nuevo primer ministro, así como por las simpatías que generaron sus propuestas, el Parlamento aprobó por mayoría los planes propuestos por el gobierno conservador.

Debemos agregar que, en lo que a la oposición parlamentaria se refiere, ésta se encontró muy limitada en su capacidad de acción desde el principio, sobre todo porque la primera minoría (el Partido Liberal) se encontraba en franco proceso de elección interna, una vez que fue oficial la renuncia de Paul Martin al frente de ese organismo político. Si se considera lo anterior, el gobierno de Harper tuvo prácticamente un primer año de gobierno sin oposición real en la Cámara de los Comunes, lo cual supo 
capitalizar a su favor, al lograr sacar adelante distintas propuestas de gobierno frente a una oposición fragmentada y visiblemente acéfala.

En este contexto, en noviembre de 2006 concluyó el proceso interno liberal, luego de resultar vencedor Stéphane Dion, tras cuatro rondas de votación. En este ejercicio interno, el nuevo líder liberal sometió a los candidatos favoritos Michael Ignatieff y Bob Rae. De inmediato, la misión de Dion fue reposicionar a su partido en el debate nacional, cuestionando las decisiones y posturas asumidas por el gobierno conservador. Sin embargo, la falta de un equipo sólido que respaldara su liderazgo provocó que comenzara a ser cuestionado y obstaculizado por los seguidores tanto de Ignatieff como de Rae, dentro de su propio partido, lo que sin duda entorpecería su papel de contrapeso frente al gobierno tory (Jeffrey, 2010: 620).

Ante este esquema contradictorio y con una disidencia liberal potencial en su contra, Stéphane Dion intentó enfrentar al primer ministro Harper durante 2007, justo cuando éste expresó su intención de no ratificar los compromisos asumidos por Canadá dentro del Protocolo de Kioto. Así, respecto de este último punto, Dion intentó sumar esfuerzos de toda la oposición para hacer frente a Stephen Harper, quien abiertamente había expresado su animadversión al Protocolo de Kioto, al calificarlo como un esquema de tipo socialista que buscaba extraer dinero de las naciones desarrolladas productoras. Además, Harper mismo insistía en que ratificarlo significaría una parálisis en la industria energética canadiense, lo que afectaría de manera grave las economías de Alberta, Terranova, Nueva Escocia, Saskatchewan y Columbia Británica (Toronto News, 2007).

Así, los temas energético y ecológico se convirtieron en asuntos recurrentes en los debates parlamentarios y, por ende, en los medios de comunicación nacionales, a través de los cuales se propaló la idea (promovida desde el gobierno conservador) de rechazar los compromisos firmados diez años antes por el gobierno liberal, pues, a su juicio, ratificar el Protocolo de Kioto significaba afectar los intereses de la poderosa industria energética en el Oeste, sobre todo en la conservadora e influyente provincia de Alberta.

Esta postura dejó un escenario político dividido entre los defensores del respeto a los acuerdos de Kioto, que obligaban a Canadá a cumplir con una serie de contribuciones económicas, debido a sus limitadas acciones para disminuir la emisión de gases de efecto invernadero y los conservadores, apoyados por la industria energética canadiense, quienes optaron por rechazar la obligatoriedad contraída y desconocer los acuerdos.

Ante este escenario, casi de manera imperceptible, el escenario político del país se configuró para preparar un nuevo proceso electoral adelantado, toda vez que el gobierno conservador y la oposición liberal no mostraban signos de llegar a acuerdo 
alguno respecto del tema energético y ecológico. Así, justo cuando los debates sobre temas ecológicos dominaban la actividad parlamentaria, el primer ministro Harper decidió insertar un nuevo tema que generó mayor polémica en el corto plazo: extender la misión militar canadiense en Afganistán hasta diciembre de 2011, lo cual encontraría una fuerte oposición de parte de los liberales, ya que este grupo defendía respetar el acuerdo original y regresar a las tropas a su país a partir de febrero de 2009.

Con esta propuesta, Harper inauguraba otro flanco en el debate político nacional, consciente de que gobierno y oposición no alcanzarían un acuerdo, lo que terminaría llevando al Parlamento a un nuevo llamado a elecciones anticipadas. La estrategia del primer ministro parecía provenir de la necesidad de su partido por aprovechar la falta de coordinación opositora, pues era evidente que Dion se enfrentaba a cuestionamientos dentro de su agrupación, lo que generaba un entorno que debilitaba su liderazgo en la Cámara de los Comunes. Esto último contrastaba con la situación de Harper, pues el primer ministro tenía absolutamente plegado a todo su partido en torno a su figura, liderazgo y decisiones.

Ante este escenario, Stéphane Dion, en su calidad de líder de la oposición, decidió presentar a mediados de 2008 un plan verde alternativo, conocido como Green Shift (Cambio verde o Plan verde), a través del cual se proponía una serie de medidas que incluyeran nuevas tasas impositivas a las empresas del ramo energético que generaran elevados niveles de dióxido de carbono. Al mismo tiempo, el Green Shift otorgaba disminuciones tributarias a las empresas que invirtieran y aplicaran programas de disminución de contaminantes de combustibles fósiles. El punto más polémico del Plan verde era la propuesta de crear un nuevo impuesto al carbón, a través del incremento en las contribuciones fiscales de todas las compañías del ramo energético nacional, productoras de diésel, combustibles ligeros, pesados, de aviación, gas natural, queroseno y carbón.

Así, a partir de que Dion dio a conocer su plan tributario alternativo en pro de la ecología, las dos posturas quedaron muy claras, al menos para los ciudadanos: por un lado, se encontraba el Partido Liberal impulsando nuevos impuestos y, por el otro, se erigía el gobernante Partido Conservador como defensor de la industria energética y de los contribuyentes. En este sentido, los conservadores ofrecieron una respuesta muy mediática y atractiva a los electores al negarse a crear nuevos impuestos, pues precisamente Stephen Harper había sido claro al respecto durante su campaña electoral anterior, en la que se comprometió a no crear nuevas contribuciones tributarias.

Mientras el debate entre liberales y conservadores se agudizaba, el Bloque Quebequense decidió mantenerse al margen y aguardar las tendencias de opinión, ya que la industria energética quebequense también resultaría afectada si aprobaba el Green Shift. En cuanto al Partido Neodemócrata, su líder, Jack Layton, manifestó 
que él no se encontraba del todo convencido de la pertinencia de hacer pagar más a quienes más tenían; que sería mejor, en cambio, discutir con calma el proyecto antes de adoptarlo, defenderlo o atacarlo (Now Public Crowd Powered Media, 2008). Todo esto significó que Stéphane Dion y el Partido Liberal irían solos en su lucha por aprobar el Green Shift en contra del gobierno conservador, pues ni los del Bloque Quebequense ni los neodemócratas se manifestaron dispuestos a asumir el costo político al adoptar un proyecto que, de entrada, se traduciría en mayores impuestos y costos para los ciudadanos. Resultaba claro que las empresas energéticas castigadas con mayores pagos de impuestos cargarían el costo directo a los consumidores.

En este sentido, conviene señalar que el mensaje de Dion no lo emitieron bien los liberales, ya que el Green Shift era más que un simple incremento de impuestos, pues por medio de éste se establecía cómo y de qué manera se redestinarían los fondos recaudados, eliminando, de paso, las emisiones contaminantes de las empresas infractoras. No obstante lo anterior, los ciudadanos canadienses vieron amenazada su economía con mayores cargas impositivas, situación que capitalizó con éxito el gobierno conservador, ya que en todo momento insistió en que no permitiría un incremento tributario.

Toda esta situación de encono entre liberales y conservadores la capitalizó el primer ministro, quien solicitaría a la gobernadora general, Michaëlle Jean, una disolución parlamentaria, argumentando parálisis en la toma de decisiones de dicho poder, en plena crisis económica mundial.

Lo que más llama la atención de esta solicitud de disolución parlamentaria fue que precisamente Harper presentó y aprobó -apoyado por el resto de los partidos- una ley que impedía a cualquier primer ministro convocar y adelantar elecciones desde el poder. Empero, esta ley no impedía que dicho primer ministro solicitara a un tercero -en este caso la gobernadora general- un llamado anticipado a elecciones, argumentando parálisis legislativa. Como era de esperarse, este llamado de Harper sorprendió a toda la clase política canadiense, pues la oposición no se encontraba preparada para comenzar campañas electorales en ese momento.

No obstante lo anterior y generando suspicacias, la gobernadora general accedió a disolver el Parlamento y convocó a nuevas elecciones federales para el 14 de octubre de 2008, acogiéndose a que la ley establecía lo siguiente: “Nada en esta sección afecta los poderes del gobernador general, incluido su poder de disolver el Parlamento a discreción del propio gobernador general" (Flanagan, 2009a: 295).

Una vez señaladas las razones jurídicas de Harper para convocar a un nuevo proceso electoral, iniciaron las campañas con el Partido Conservador al frente en las encuestas de opinión, mientras que el Partido Liberal descendía, sobre todo a raíz de una campaña tory diseñada para cuestionar las habilidades políticas de Stéphane Dion como líder. Al mismo tiempo, la estrategia conservadora de señalar el Green 
Shift como un intento de incrementar impuestos que incluirían la gasolina, generó otro elemento adverso para los liberales.

Derivado de lo anterior, el Partido Liberal se rezagó en las encuestas respecto de sus rivales tories, lo que generó apremio entre sus filas, pues el proceso electoral de 2008 corría el riesgo de convertirse en una derrota histórica para su causa. A partir de ese momento, las campañas mostraron dos posturas divergentes: la primera, con un Stéphane Dion que defendía el Green Shift como tema central de campaña, ponderando los beneficios ecológicos y tributarios que aquél representaba; mientras que los conservadores, con Stephen Harper al frente, insistían en que el Green Shift significaba mayores impuestos para las empresas y los trabajadores.

Tomando en cuenta ambos aspectos, la estrategia tory se concentró en aprovechar el clima de miedo ante la crisis económica mundial para asegurar los votos de gente temerosa de perder sus empleos y pagar más impuestos. Así, los estrategas conservadores diseñaron una campaña centrada en la imagen del líder liberal, afirmando que Stéphane Dion era un riesgo para el país y la economía. Así, transmitieron esa idea al resto de la población. Para alcanzar esos fines, el Partido Conservador diseñó y difundió de forma repetitiva durante toda la campaña tres mensajes: el primero incluía la imagen de Dion con el eslogan "Impuestos a todo"; el segundo mostraba una fotografía del primer ministro con la leyenda "Estamos mejor con Harper"; en cambio, el tercer mensaje de campaña presentaba una fotografía de Dion encogiendo los hombros, con expresión extraviada y con la leyenda "Stéphane Dion: No vale la pena el riesgo" (Flanagan, 2009: 301).

Los tres elementos descritos no dejaban lugar a dudas de que la campaña tory se centraba en atacar y envilecer la imagen personal de Stéphane Dion, en tanto que la del Partido Liberal enfocó su campaña en proponer y plantear los objetivos del Green Shift. Esta estrategia permitió a sus rivales tories atacar impunemente al líder liberal, sin una respuesta de éstos hacia la figura del primer ministro. Esa dinámica generó una inercia que hacía prever un triunfo mayoritario de la causa tory. Esta situación generó que tanto liberales como neodemócratas diseñaran un rápido plan de gobierno que supondría millonarios incrementos para el cuidado infantil.

Precisamente el tema de los apoyos infantiles asestó un fuerte golpe a la meta conservadora de alcanzar un gobierno de mayoría, pues Stephen Harper desestimó la propuesta al afirmar que él personalmente se encontraba en contra de dichos incrementos, ya que provocarían serios déficit e incrementos tributarios (Canada.com, 2008). Esta afirmación mostró al primer ministro como un político más preocupado por mantener las finanzas sanas a toda costa, que en el cuidado de la salud de todos los niños canadienses. La consecuencia de sus palabras fue una disminución en la intención de voto para su causa a tan sólo tres semanas de las elecciones, propiciando 
-según datos expresados por la casa encuestadora Ipsos- un repunte del Partido Neodemócrata, pero sin manifestar mejora alguna para la causa del Partido Liberal (Blaze, 2011). Lo anterior, si bien mantenía aún al frente a los tories, evidenciaba que su ventaja disminuía poco a poco, amenazando el objetivo primordial de alcanzar un gobierno mayoritario, el cual había sido la razón de este llamado anticipado a elecciones. Así, los debates televisivos del $1^{\circ}$ y 2 de octubre cobrarían un especial significado, pues sería la última oportunidad que tendrían los líderes de los principales partidos contendientes para incrementar drásticamente los votos a su favor, a sólo dos semanas de los comicios.

El primero de los debates se llevó a cabo en francés; su difusión tuvo mayor impacto en la provincia de Quebec (obviamente por su francofonía), lo que sirvió de preámbulo para conocer el contenido y las características del segundo debate (en inglés), pues por ser este país en su mayoría anglófono, en los hechos suele tener un impacto nacional el idioma en que los contendientes presentan sus propuestas e intercambian acusaciones. Una vez iniciado el segundo debate, el primer ministro Harper empezó a ser increpado por todos sus contendientes, al compararlo con el entonces presidente de Estados Unidos, George W. Bush, precisamente por su intención de extender la presencia de tropas canadienses en Afganistán. Sin embargo, la estrategia de Harper se centró en eludir todo enfrentamiento directo con sus oponentes, y mediante mensajes breves y sencillos hizo hincapié en que su gobierno había logrado evitar que Canadá cayera en crisis económica y quiebras bancarias, tal como había sucedido con el resto del mundo occidental desarrollado, incluido Estados Unidos.

Esta dinámica prevaleció durante la mayor parte del debate, con una oposición que cuestionaba las acciones de gobierno y un primer ministro que, con una sonrisa irónica y voz suave y pausada, ignoraba los ataques, centrando su discurso en que el gobierno trabajaba para salvaguardar el bienestar de las familias canadienses, muestra de ello era su negativa a incrementar impuestos, tal como lo proponían los liberales (You Tube, 2008).

Sin embargo, pese a la estrategia de Harper durante los debates, lo cierto era que las encuestas mostraban una disminución de las preferencias por el Partido Conservador, en proporción al incremento del Liberal, que, según las casas encuestadoras Ipsos y Strategic Council, ubicaban a los tories a cinco puntos de ventaja respecto de sus rivales liberales, a tan sólo tres días de los comicios (Blaze, 2011). Al parecer, la razón de este repunte opositor al final de las campañas se debió a la mala imagen que dejó Stephen Harper al mostrar desinterés por el bienestar de los niños canadienses, ante su negativa por incrementar recursos para el cuidado y mejor desarrollo infantiles. Esto contrastaba con el proyecto defendido por los liberales y los neodemócratas, quienes concentraron la parte final de su campaña en ponderar ese asunto a nivel nacional, soslayando todo lo demás. 
Pero justo cuando el resultado parecía desfavorable a la causa tory, a través de una práctica que incluso es ilegal en muchos países que se encuentran en pleno proceso electoral, la agencia oficial Statistics Canada reportó que durante septiembre, bajo la administración conservadora, se habían creado ciento siete mil empleos, lo que significaba el volumen más grande desde 1976. Esto se dio a conocer justo el mismo día en que el foro del Banco Mundial señalara que los bancos canadienses eran los más estables y sólidos de todo el mundo (Flanagan, 2009: 310). Estos dos asuntos que mencionamos se difundieron a nivel nacional por los medios de comunicación, justo en momentos en que el resto del mundo se encontraba sumergido en quiebras y rescates bancarios, además de elevados niveles de desempleo como producto de la peor crisis del capitalismo mundial, desde el difícil trance de 1929.

En los hechos, estos dos anuncios de carácter mediático masivo sirvieron para que Stephen Harper centrara la parte final de la campaña en torno al tema de que su gobierno había logrado una estabilidad económica única en el mundo, sobre todo gracias a las políticas puestas en práctica por los estrategas y administradores tories. El resultado fue un repunte agudo que permitiría al Partido Conservador mantenerse en el poder, pero, otra vez, encabezando un gobierno de minoría.

Según los resultados oficiales (véase el cuadro 1), el Partido Conservador incrementó su presencia en la Cámara de los Comunes al alcanzar 143 curules, frente a 77 del Partido Liberal, 49 del Bloque Quebequense y 37 del Partido Neodemócrata. Dichos números, si bien reforzaban la presencia tory en el Parlamento, dejaban en claro que el repunte alcanzado por los conservadores en los últimos tres días de campaña no había sido suficiente para cumplir la meta de lograr un gobierno de mayoría, que, como ya se dijo, había sido el objetivo de Stephen Harper cuando solicitó la disolución parlamentaria a la gobernadora general.

\begin{tabular}{|lcccc|}
\hline \multicolumn{5}{c|}{ Cuadro 1 } \\
ELECCIONES FEDERALES, 14 DE OCTUBRE DE 2008 & \\
Partido & $\begin{array}{c}\text { Diputados (Cámara } \\
\text { de los Comunes) }\end{array}$ & $\begin{array}{c}\text { Porcentaje } \\
\text { de escaños }\end{array}$ & Votos válidos & $\begin{array}{c}\text { Porcentaje } \\
\text { de voto }\end{array}$ \\
Partido Conservador & 143 & 46.4 & 5209069 & 37.7 \\
Partido Liberal & 77 & 25 & 3633185 & 26.3 \\
Bloque Quebequense & 49 & 15.9 & 1379991 & 10 \\
Partido Neodemócrata & 37 & 12 & 2515288 & 18.2 \\
Otros & 2 & 0.6 & 1096761 & 7.8 \\
Total & 308 & 99.9 & 13834294 & 100 \\
Fuente: Elaboración propia, con datos de Parliament of Canada (2011a; 2011b). & \\
\hline
\end{tabular}


Entre lo más sobresaliente de las elecciones de 2008 (véase el cuadro 2) fue la consolidación del Partido Conservador en el oeste del país, así como en la provincia de Ontario, en donde, con 51 curules terminó afirmando su posición parlamentaria a nivel nacional. Por su parte, la proporción de representantes del Partido Liberal fue disminuyendo cada vez más, perdiendo espacios vitales para su causa precisamente también en Ontario. En lo que corresponde al Bloque Quebequense, esta agrupación logró mantener su considerable presencia en la provincia de Quebec, fortaleciendo su posición como tercer partido en la Cámara de los Comunes.

Mientras tanto, el Partido Neodemócrata continuaba su línea ascendente bajo el liderazgo de Jack Layton, al ganar treinta y siete diputaciones. Lo más trascendente para la causa neodemócrata fue que su partido había logrado finalmente alcanzar representaciones en todas y cada una de las regiones del país, al sorprender en Alberta y Quebec con una curul, respectivamente.

En cuanto a Stephen Harper, fue claro que su mayor problema, una vez confirmada su victoria por minoría, consistiría en que su administración tendría que lidiar con una oposición mayoritaria, la cual se encontraría muy resentida con el primer ministro, sobre todo después de incumplir su promesa de no llamar a elecciones anticipadas desde el poder, con el principal objetivo de obtener una ventaja política de ello.

\begin{tabular}{|c|c|c|c|c|c|c|}
\hline \multicolumn{7}{|c|}{$\begin{array}{c}\text { Cuadro } 2 \\
\text { COMPOSICIÓN DE LA CÁMARA DE LOS COMUNES POR PARTIDO POLÍTICO } \\
\text { DESPUÉS DE LAS ELECCIONES FEDERALES DEL } 14 \text { DE OCTUBRE DE } 2008\end{array}$} \\
\hline Región & $\begin{array}{c}\text { Partido } \\
\text { Conservador }\end{array}$ & $\begin{array}{l}\text { Partido } \\
\text { Liberal }\end{array}$ & $\begin{array}{c}\text { Partido } \\
\text { Neodemócrata }\end{array}$ & $\begin{array}{c}\text { Bloque } \\
\text { Quebequense }\end{array}$ & $\begin{array}{c}\text { Otros/ } \\
\text { independientes }\end{array}$ & $\begin{array}{l}\text { Total por } \\
\text { región }\end{array}$ \\
\hline $\begin{array}{l}\text { Columbia } \\
\text { Británica }\end{array}$ & 22 & 5 & 9 & - & - & 36 \\
\hline Alberta & 27 & _ & 1 & - & - & 28 \\
\hline $\begin{array}{l}\text { Provincias de } \\
\text { las Praderas }\end{array}$ & 22 & 2 & 4 & - & - & 28 \\
\hline Ontario & 51 & 38 & 17 & - & - & 106 \\
\hline Quebec & 10 & 14 & 1 & 49 & 1 & 75 \\
\hline $\begin{array}{l}\text { Provincias } \\
\text { del Atlántico }\end{array}$ & 10 & 17 & 4 & - & 1 & 32 \\
\hline $\begin{array}{l}\text { Territorios } \\
\text { del Norte }\end{array}$ & 1 & 1 & 1 & - & - & 3 \\
\hline $\begin{array}{l}\text { Total por } \\
\text { partido }\end{array}$ & 143 & 77 & 37 & 49 & 2 & 308 \\
\hline
\end{tabular}


En este contexto, y en cuanto fueron oficiales los resultados de la elección de 2008, trascendería que los líderes de los partidos Liberal, Neodemócrata y Bloque Quebequense se encontraban negociando alcanzar un gobierno de coalición mediante un voto de censura al primer ministro, esto en cuanto el gobierno conservador les diera la primera oportunidad, la cual llegó rápidamente, justo cuando Stephen Harper -buscando ganarse mayores simpatías populares- propuso reducir impuestos, pero a través de la eliminación de subsidios gubernamentales a los partidos políticos, situación que amenazaba la supervivencia de los demás partidos representados en el Parlamento.

Lo anterior respondía a que las otras agrupaciones políticas, a diferencia de los tories, no contaban con la poderosa maquinaria recaudadora empresarial conservadora, que a través de generosas donaciones de grupos corporativos bien podría superar la condición de reducción presupuestaria para sacar adelante de cualquier manera sus campañas políticas futuras.

Paralelamente, la propuesta de prohibir el derecho de huelga a los burócratas terminaría por hacer efectiva la alianza opositora, que se volvió oficial el $1^{\circ}$ de diciembre de 2008, al informar al Parlamento su decisión de conformar por primera vez en la historia del país un nuevo gobierno de coalición, con Stéphane Dion al frente como primer ministro. Al lado del líder liberal Stéphane Dion -y cogobernando- se ubicaría el Partido Neodemócrata, administrando seis de los veinticuatro ministerios (Kilpatrick, 2008). Dicha alianza contaba con la promesa del Bloque Quebequense en el sentido de no interferir en las acciones de gobierno durante los siguientes dieciocho meses (свс News, 2008). Este gobierno sería oficial a partir del lunes 8 de enero, justo después de que la gobernadora general, Michaëlle Jean, regresara de una gira de trabajo por Europa.

Sin embargo, en un rápido giro de las circunstancias, el primer ministro Harper inició una veloz campaña nacional de legitimación, que incluyó un mensaje en cadena nacional, a través del cual señalaría que la oposición se encontraba amenazando la economía y la democracia del país por motivaciones políticas. Por este motivo, él (Harper) en su calidad de jefe de gobierno, utilizaría todos los medios a su alcance para defender la economía y al país en su conjunto (Свс Digital Archives, 2008). De acuerdo con lo anterior y como parte de esta estrategia, el primer ministro pactó una reunión privada el día 4 de diciembre de 2008 con la gobernadora general, una vez que ella adelantara su retorno al país. En esta reunión, el primer ministro solicitó a la gobernadora general decretar una prórroga parlamentaria obligada.

El argumento principal de Stephen Harper fue otorgar más tiempo a su gobierno para elaborar una nueva propuesta presupuestaria para el ejercicio 2009. Una vez escuchados los argumentos del primer ministro, la gobernadora general accedió de inmediato a suspender toda acción parlamentaria hasta el 26 de enero de 2009, evitando 
automáticamente el ascenso de un gobierno de coalición. Lo anterior fue resultado de una inusual alianza desde el poder entre el primer ministro conservador y la gobernadora general, pues su acuerdo cerraba la puerta a un gobierno de coalición conformado por la mayoría opositora en la Cámara de los Comunes.

Esta concertación política entre Harper y la gobernadora general fue aprovechada por las elites liberales para destituir a Stéphane Dion, pues se encontraban en total desacuerdo de cogobernar con la izquierda neodemócrata del país. Por esta razón, y en un golpe interno, la dirigencia liberal decidió pedir la renuncia inmediata a su líder, quien al carecer de un equipo sólido de trabajo que lo respaldara no tuvo más opción que acceder a la petición de su partido y renunciar no sólo al liderazgo liberal, sino también a la posibilidad de ser primer ministro y encabezar un gobierno de coalición con los neodemócratas.

Sin duda, lo más revelador de este golpe dentro del Partido Liberal fue el hecho de que sus propias elites prefirieron que renunciara al poder -y mantener al Partido Conservador en el gobierno-, antes que permitirse cogobernar con la izquierda. Con esta acción, resultaba más patente la proclividad de las elites liberales y conservadoras a compartir los mismos intereses, condición que, en la práctica, ha vuelto posible los constantes e ininterrumpidos relevos entre ambos grupos políticos en la toma de poder desde 1867. Así, la decisión asumida por las elites liberales al evitar que la izquierda accediera a una parte considerable del poder en Canadá, en la práctica ayudó a consolidar el duopolio político prevaleciente entre liberales y conservadores.

A partir de ese momento, el grave problema para el Partido Liberal en el futuro sería cómo convencer a los votantes de que su agrupación era realmente distinta a sus rivales del Partido Conservador. Finalmente, una vez ratificada la salida de Stéphane Dion, las elites de su partido decidieron imponer a Michael Ignatieff como líder interino, quien, una vez en funciones, decidió respaldar al gobierno conservador de Stephen Harper, aceptando su nueva propuesta presupuestaria, que por cierto eliminaba todos los asuntos polémicos que generaron controversias políticas entre las filas opositoras en el Parlamento.

\section{LA ELECCIÓN DE 2011: ENTRE LA CONSOLIDACIÓN MAYORITARIA DE LA DERECHA CONSERVADORA, EL REPLIEGUE LIBERAL Y EL ASCENSO DE LA IZQUIERDA COMO PRIMERA OPOSICIÓN PARLAMENTARIA}

Una vez ratificado el gobierno conservador de Stephen Harper, la actividad parlamentaria se centró durante los primeros meses en el tema de la presencia militar canadiense en Afganistán, ya que el gobierno tory buscaba extender dicha misión más allá de 
su plazo original (pactado para febrero de 2009). Lo anterior ocurría al mismo tiempo que el Partido Liberal se enfrentaba al dilema de extender el liderazgo de Michael Ignatieff, aún después de las elecciones internas programadas para mayo de 2009. Esto obedecía a que su imposición como líder liberal había sido en carácter de interinato, y con excepción de Wilfrid Laurier, en el siglo XIX, el Partido Liberal había decidido no prolongar ningún liderazgo interino más allá del plazo convenido. De este modo, en su afán por extender la presencia de Ignatieff al frente del partido, las elites liberales contemplaron la posibilidad de cambiar los usos y costumbres partidistas, con el fin de extender su gestión como líder después de las elecciones internas.

Esta situación generó nuevos malestares entre las filas liberales pues -debe subrayarse- precisamente el ascenso de su predecesor, Stéphane Dion, se había dado como una manifestación de rechazo hacia la figura de Ignatieff, toda vez que durante la convención de 2006 la mayoría de los delegados habían decidido conformar bloques opositores de alianza, sobre todo para impedir el ascenso de Ignatieff. Así, en medio de esta tensión interna, el otro candidato con posibilidades en 2009, Bob Rae, decidió renunciar a la contienda interna para no generar mayores fracturas partidistas, situación que dejó el camino libre a Michael Ignatieff para contender por el liderazgo liberal como candidato único. Por este motivo, en la convención liberal de mayo de 2009, su elección fue automática, al concentrar el 97 por ciento de los votos de los poco más de dos mil delegados (CTv News, 2009).

No obstante lo anterior, cabe señalar que el número de votantes presentes en la convención de mayo de 2009 fue menor en un 55 por ciento a los delegados votantes presentes en la convención interna que eligió a Stéphane Dion en noviembre de 2006, pues en esta última serían casi cuatro mil ochocientos los delegados participantes en dicho proceso interno (Parliament of Canada, 2011a; 2011b). Esto parece obedecer a que la molestia entre los representantes liberales llegó a tales niveles que muchos prefirieron no asistir a la convención nacional, con tal de no legitimar con su voto a un líder con quien no se identificaban. ${ }^{1}$

Mientras esto ocurría con el Partido Liberal, en el Parlamento Michael Ignatieff se encontraba frente a la compleja problemática de encabezar a una oposición que no se sentía representada por él, toda vez que los liderazgos del Partido Neodemócrata (Jack Layton) y del Bloque Quebequense (Gilles Duceppe) le recriminaban haber

\footnotetext{
${ }^{1}$ Aunado a lo anterior, debe señalarse que para el proceso interno de 2009 las elites liberales decidieron abrir la elección interna no sólo a delegados, sino también a cualquier adherente o simpatizante del partido, en un claro intento por incrementar la participación y el número de votantes. Sin embargo, esta estrategia no sólo falló, sino que evidenció el malestar de las bases liberales con la dirigencia, pues aun así la asistencia al evento de legitimación de Ignatieff se redujo en proporción de dos a uno, en comparación con la convención nacional realizada dos años y medio antes.
} 
rechazado el acuerdo alcanzado por su predecesor para conformar un gobierno de coalición y sustituir así al gobierno tory.

Si se considera lo expuesto hasta aquí, puede señalarse que Ignatieff encabezaba un partido cuyas bases no lo aceptaban, debido a su imposición y prolongación en el poder desde las elites, mientras que en el Parlamento dirigía a una oposición que tampoco lo reconocía como su líder, debido a sus decisiones unilaterales y a su fuerte tendencia conservadora. Al respecto, incluso el académico conservador de la Universidad de Calgary, Tom Flanagan, señala: “Mientras que Dion empujó a los liberales hacia la izquierda, incluso al grado de conformar una coalición con el PND [Partido Neodemócrata] y el вQ [Bloque Quebequense], Ignatieff se está moviendo de nuevo al centro, adaptando posiciones similares a Harper en un gran número de asuntos clave" (Flanagan, 2009a: 326).

Debido a lo antes expuesto, Ignatieff se concibió entonces como un líder liberal más conciliador con sus rivales tories en el poder, esperando de esta forma tener la oportunidad de relevarlos después de algún desatino que, por sus dimensiones, lograra aglutinar a toda la oposición en torno a su figura. De acuerdo con esta lógica, Michael Ignatieff intentó sumar a toda la oposición después del receso parlamentario del verano de 2009, argumentando falta de transparencia en los gastos públicos, en un intento por empujar un voto de censura en contra del primer ministro Harper y adelantar elecciones. Sin embargo, la negativa del Partido Neodemócrata asestaría la primera gran derrota política al líder liberal, dejando en claro que si Ignatieff quería gozar del apoyo neodemócrata en el futuro, tendría entonces que trasformar sus estrategias de acercamiento hacia ellos, ya que aún estaba muy fresca en la memoria de Jack Layton y sus diputados la negativa del nuevo liderazgo liberal para conformar un gobierno de coalición.

Así, este intento fallido por remover al primer ministro conservador puso en evidencia la división interna de la oposición parlamentaria, pues era obvio que mientras el Partido Neodemócrata no se sumara al resto de las fracciones opositoras, cualquier intento por remover a Stephen Harper fracasaría rotundamente. En este sentido, la votación suscitada por Ignatieff el $1^{\circ}$ de octubre de 2009 otorgó solamente ciento diecisiete votos a favor, por ciento cuarenta y cuatro en contra del Partido Conservador. Esto convirtió a los neodemócratas, con sus treinta y siete votos, en el elemento clave para mantener o destituir al primer ministro tory (Ljunggren, 2009).

De esta forma, mientras la oposición parlamentaria no encontraba cómo ponerse de acuerdo, el gobierno de Stephen Harper iba fortaleciendo su posición a nivel nacional, respaldado en un discurso de crecimiento económico y reducción de impuestos para las familias canadienses. Si a lo anterior se sumaba el fracaso de Ignatieff en la votación del $1^{\circ}$ de octubre, era entonces más claro que el gobierno conservador iba 
ganando espacios ante la opinión pública, pues, frente al electorado, Harper se erigía como un político que, no obstante encabezar un gobierno de minoría parlamentaria, lograba sacar adelante sus propuestas de estabilidad económica y reducciones tributarias.

Toda esta dinámica favorable a su causa animaría nuevamente a Harper a proponer en el Parlamento una extensión de la presencia militar canadiense en territorio afgano, cuyo término se encontraba muy cercano. Este tema en particular, inicialmente encontró uniformidad opositora, pues los tres partidos rechazaron cualquier intento de extensión militar más allá de lo pactado originalmente. Esta propuesta de Stephen Harper se dio justo cuando la mayoría opositora había decidido crear una comisión parlamentaria de investigación, que trabajara a fondo en las acusaciones de presuntos actos de tortura cometidos por militares canadienses en contra de miembros de la milicia talibán. No obstante lo anterior, el gobierno tory rechazó facilitar los trabajos de dicha comisión, argumentando que la información era clasificada, pues involucraba temas de seguridad nacional.

Esta situación generó cierta animadversión pública hacia la administración de Harper, quien, ante la caída en sus niveles de popularidad y el riesgo que implicaba ser destituido mediante un voto de censura, decidió acudir nuevamente ante la gobernadora general, Michaëlle Jean, a solicitarle una nueva prórroga parlamentaria efectiva del 30 de diciembre de 2009 al 3 de marzo de 2010. El argumento para solicitar esta prórroga fue la celebración de los Juegos Olímpicos de Invierno de 2010, en Vancouver.

Así, no obstante el malestar de la mayoría opositora por la estrategia política efectuada por Stephen Harper, la gobernadora general accedería a la petición del primer ministro, decretando por segunda vez en su gestión (en el mismo año) un nuevo receso parlamentario. Conviene señalar que este receso congelaba toda investigación relativa a las acciones de militares canadienses en territorio afgano, al tiempo que alargaba los debates y discusiones para extender la misión militar canadiense en Medio Oriente. También es oportuno señalar que esta segunda prórroga de 2009 se dio justo después de que Michael Ignatieff, en su calidad de líder liberal, rechazara una propuesta neodemócrata de Jack Layton dirigida a imposibilitar a cualquier primer ministro la solicitud de nuevas prórrogas parlamentarias forzadas en el futuro. Este rechazo de Ignatieff no hizo otra cosa que acentuar las diferencias entre los partidos Liberal y Neodemócrata.

Una vez concluidos los juegos olímpicos de invierno, el gobierno de Stephen Harper propuso un plan de investigación de los actos de tortura en los que estuvieran presuntamente involucrados militares canadienses en Afganistán. Tal plan contemplaba una desclasificación de los documentos requeridos por la comisión parlamentaria encargada de la investigación, pero limitaba la liberación de la información 
contenida incluso para los miembros de la comisión. Lo anterior sería posible gracias a los filtros de seguridad que impidieran a los diputados encargados extraer, fotocopiar, fotografiar, o incluso transcribir o hacer cualquier tipo de anotaciones de los documentos entregados por el gobierno conservador. Al mismo tiempo, toda la información recabada sólo se revelaría a las cúpulas partidistas, sin posibilidad de hacer extensivos los resultados a la opinión pública o al resto del Parlamento.

Esta propuesta conservadora se conoció como "Memorandum of Understanding" ("Memorando de entendimiento") 2 y, si bien su negociación tardó cuatro meses en concretarse, lo más trascendente fue que el acuerdo se firmó a tan sólo dos días del receso parlamentario de verano de 2010, situación que desarticulaba de facto cualquier intento de la oposición para solicitar una moción de censura por desacato en contra del primer ministro. En este sentido, debe agregarse que la negociación en sí representó una nueva fractura y división entre los partidos opositores, pues Michael Ignatieff y Gilles Duceppe del Bloque Quebequense fueron los dos líderes que decidirían firmar el acuerdo. Esto una vez que el líder neodemócrata Jack Layton considerara como inaceptables las condiciones restrictivas propuestas por Stephen Harper para revisar los documentos solicitados.

Como era de esperarse, la decisión final de Ignatieff al aceptar los términos propuestos por el primer ministro conservador generó nuevos reclamos entre las filas neodemócratas, pues con la firma del documento se descartaba una oportunidad para someter a los conservadores en el poder y de paso revelar actitudes indebidas que involucraran al propio gobierno tory en actos de encubrimiento de información frente a la opinión pública, no sólo de Canadá, sino también del resto del mundo.

Posteriormente, cuando reinició la actividad parlamentaria, después del receso del verano de 2010, el gobierno conservador puso en marcha una nueva campaña para señalar a Michael Ignatieff como un político displicente en temas de seguridad interna, y poco interesado en la seguridad física de los militares canadienses en servicio en Afganistán. El nivel de presión interna ejercida por el gobierno tory en contra de Ignatieff lo orillaría a negociar, en noviembre de 2010, a espaldas de su propio partido, un acuerdo secreto con el primer ministro conservador, con el fin de extender la misión militar canadiense en Afganistán hasta el 2014.

Esta decisión de Ignatieff, si bien puso fin a las críticas provenientes del gobierno, le abriría, por otro lado, nuevos flancos de ataque, pero ahora desde la oposición y la opinión pública. Aunado a lo anterior, dentro de su partido fue evidente la molestia en contra de su líder, pues varios parlamentaristas liberales afirmaban haberse enterado del hecho a través de la prensa escrita o la televisión (Taber, 2010). Así, los

\footnotetext{
${ }^{2}$ Para una revisión completa del documento, véase Parliament of Canada (2010).
} 
cuestionamientos hacia el estilo vertical de Michael Ignatieff fueron creciendo, pues -hasta el momento en que se oficializó este acuerdo secreto con el primer ministroIgnatieff mismo se había caracterizado por ofrecer una posición contraria a la extensión de la presencia militar canadiense en Afganistán, tal y como lo afirmaba oficialmente todo el Partido Liberal.

Desde luego que los hechos anteriores fueron conformando pequeñas victorias políticas para el gobierno tory, que se acumularon de tal modo que en el segundo semestre de 2010 el Partido Conservador y su líder y primer ministro, Stephen Harper, ya habían logrado reposicionarse frente a la opinión pública. Así, la falta de acuerdos opositores y las contradicciones y decisiones verticales del liderazgo liberal terminaron fortaleciendo cada vez más al gobierno minoritario conservador, toda vez que a principios de 2011 superaba por diez puntos a sus rivales liberales en intención de voto. ${ }^{3}$

Una vez agudizada la falta de consenso y cooperación entre los partidos opositores en el Parlamento, fue más evidente la fortaleza alcanzada por el gobierno minoritario de Stephen Harper, pues ya encaraba en el 2011 una posición muy favorable frente a todos sus rivales. Esta realidad obligó a la creación de mecanismos de acercamiento y coordinación opositora dentro del Parlamento. En este contexto, el tema de una posible compra de sesenta y cinco aviones de combate F-35 se posicionó como el asunto central en los debates parlamentarios, unificando así finalmente la postura entre liberales, neodemócratas y el Bloque Quebequense, quienes se opusieron al proyecto del gobierno tory de invertir dieciséis mil millones de dólares para la adquisición de esas aeronaves.

Al mismo tiempo, surge la propuesta del gobierno conservador de impulsar la construcción de modernas supercárceles en todo Canadá, mientras el país gozaba de los niveles de criminalidad más bajos de los últimos años, así como la propuesta de criminalizar a pequeños productores domésticos de plantas de mariguana, convirtiéndolos en potenciales delincuentes. Estos dos factores reforzaron la unificación de criterios entre los partidos opositores a Harper, que en su conjunto exigieron claridad de cuentas en el presupuesto planteado tanto para la compra de los F-35, así como para la construcción de las llamadas supercárceles.

El motivo de este malestar opositor obedecía a que, según datos brindados por el Partido Liberal, la construcción de esas prisiones costaría entre diez mil y trece mil millones de dólares (Liberal Party, 2011). Pero no sólo eso, sino que también la compra de los sesenta y cinco aviones de combate F-35 duplicaría su presupuesto original, al pasar de los dieciséis mil millones de dólares a los treinta mil millones. Aunado a lo

${ }^{3}$ Las cifras y porcentajes se corroboran en Three Hundred Eight.Com (2006 y 2011). 
anterior, Michael Ignatieff afirmó, con base en informes independientes realizados por especialistas de varios países, que el costo de las aeronaves se incrementaría un 4 por ciento cada año, lo que significaba que la deuda pública para pagar los F-35 tardaría treinta años en cubrirse y no veinte, según lo señalaba el gobierno conservador en su propuesta original (CTV News, 2011), además de que la entrega de las aeronaves finalizaría hasta el año 2023 (Canada.com, 2012).

Al mismo tiempo, comenzaban a multiplicarse los cuestionamientos acerca de que la transacción no incluía los motores de las aeronaves, tampoco su mantenimiento, situación que volvía previsible un natural incremento del costo original de dieciséis mil millones de dólares planteado por el gobierno tory (Pugliese, 2011). Por este motivo, los partidos opositores solicitaron al gobierno toda la documentación oficial que detallara los montos exactos de las transacciones propuestas ante la Cámara de los Comunes.

Sin embargo, el primer ministro Harper se negó a entregar esa información, argumentando que ésta involucraba temas de seguridad nacional y que, por ende, no le era posible revelar ante el Parlamento y la opinión pública los detalles de la posible compra de los F-35. Pese a lo anterior, la oposición, a través de su líder Michael Ignatieff, insistió en revisar todos los documentos que involucraran el uso de recursos públicos para gastos de defensa, obteniendo una negativa reiterada por parte de las autoridades conservadoras. Esta actitud retadora de Harper fue colocando a toda la oposición ante un escenario muy desfavorable, pues cada rechazo y desacato del primer ministro evidenciaba la fortaleza y seguridad que había alcanzado su administración, sobre todo gracias a las divisiones y falta de consensos de la mayoría opositora.

Tomando en cuenta los elementos precedentes, pronto fue evidente que los partidos opositores en la Cámara de los Comunes no se encontraban en posición favorable -según las encuestas- para hacer un llamado adelantado a elecciones. Empero, el reiterado rechazo a todas sus solicitudes de transparencia, junto con la actitud del gobierno de Harper, en el sentido de ignorar abiertamente a la oposición en su conjunto, al final dejó sin margen de maniobra a los diputados liberales, neodemócratas y del Bloque Quebequense. De esta manera, ante la falta de respuesta del gobierno tory, la oposición no tuvo otra alternativa que solicitar al recién nombrado gobernador general, David Loyd Johnston, una moción de censura en contra del primer ministro Harper por desacato.

Para hacer posible este llamado, y su posterior disolución parlamentaria a través del gobernador general, la mayoría opositora se impuso en una paradójica votación con ciento cincuenta y seis votos a favor de la moción de censura (Partido Liberal, Partido Noedemócrata y Bloque Quebequense), contra ciento cuarenta y cinco votos del Partido Conservador (ввС News, 2011). Por cierto, cabe decir que esa votación resultó 
paradójica, pues a quienes terminó favoreciendo el llamado adelantado a elecciones fue precisamente al Partido Conservador, por encontrarse como puntero en todas las encuestas.

Se consideraría que la moción de censura aprobada por la mayoría parlamentaria el 25 de marzo de 2011 terminó convirtiéndose precisamente en lo que el primer ministro Harper buscaba, pues de inmediato arrancó una campaña electoral con más de diez puntos de ventaja sobre sus rivales más cercanos (en este caso el Partido Liberal). En estas circunstancias, iniciaron cinco semanas y media de campañas que concluirían con las elecciones generales, convocadas para el día 2 de mayo de 2011.

Esta campaña experimentaría tres etapas o periodos característicos que proyectaron su resultado final: la primera se caracterizó por las acusaciones de Stephen Harper, señalando que la oposición preparaba en secreto un gobierno de coalición, consciente de que ésta sería la única posibilidad de salir derrotado en las elecciones (Macleans. ca, 2011). Al mismo tiempo, no dejaba pasar la oportunidad para afirmar que los demás partidos eran los únicos responsables de este llamado electoral adelantado.

La insistencia en el discurso de Harper obligó a que Michael Ignatieff declarara ante la prensa que él personalmente no compartía la idea de las coaliciones y que incluso las rechazaba (CTV.CA, 2011). ${ }^{4}$ Con esta afirmación, Ignatieff condenaría a su partido a la derrota, pues un gobierno coaligado habría sido la única posibilidad real de superar a los conservadores y sacarlos del poder.

Una vez solucionada la emergencia de Harper por desarticular la posibilidad de un gobierno de coalición, se pasó a una segunda etapa en las campañas, en las que las acusaciones mutuas fueron el denominador común. Esta segunda parte se caracterizó por los señalamientos del gobierno conservador, en el sentido de que los partidos opositores eran poco nacionalistas y solidarios con el riesgo que corría el personal militar canadiense destacado en Afganistán, al tiempo que afirmaba que la oposición no sería capaz de solventar los desafíos económicos prevalecientes.

Por su parte, la oposición acusaría al gobierno tory de ocultar información a la opinión pública acerca del papel de las tropas canadienses en territorio afgano, así como de negarse a entregar documentación referente al costo de distintos proyectos de ley.

Al final, esta segunda etapa de descalificaciones mutuas no generó grandes cambios entre los votantes, pues, de acuerdo con el seguimiento de Three Hundred Eight (realizado de enero de 2009 a diciembre de 2011), el Partido Conservador seguía manteniendo los mismos diez puntos de ventaja sobre los liberales, a tan sólo dos semanas y media de las elecciones (Three Hundred Eight.com, 2011).

\footnotetext{
${ }^{4}$ La población canadiense no tiene una opinión favorable sobre los gobiernos de coalición, situación que lo vuelve un tema muy delicado frente a los electores en tiempo de campañas.
} 
Esta fricción e inmovilidad en las encuestas previas a la elección darían paso a la tercera y última etapa de las campañas, que se identifica a partir del primer debate en inglés del 12 de abril. Lo trascendente de esta tercera etapa fue que el Partido Conservador mantuvo su posición, mas no así el Partido Liberal, que experimentó una aguda caída en el nivel de intención de voto, en proporción exacta al incremento del Partido Neodemócrata. Los factores que detonaron estos cambios se identifican en el debate mismo, a través de dos circunstancias precisas: la capacidad del primer ministro Harper en eludir con éxito los ataques de sus oponentes y que fue precisamente el momento en que Jack Layton acusó a Michael Ignatieff (en televisión abierta y a nivel nacional) de mantener un discurso incongruente, pues en su tiempo no mostró respeto por el Parlamento en su calidad de líder de la oposición, al faltar al 70 por ciento de las votaciones legislativas. Incluso Layton agregaría: "Si usted quiere ser primer ministro, primero tiene que ser miembro del Parlamento. ¿Sabe usted?, la mayoría de los canadienses tiene que ir a trabajar si quiere una promoción laboral" (YouTube, 2011).

De inmediato y sin dar oportunidad a su aludido, Layton dejó en claro que mientras él se encontraba luchando en el Parlamento en contra de propuestas regresivas del gobierno conservador, Ignatieff simplemente se ausentaba de los debates y las votaciones. Lo más grave del momento para el líder del Partido Liberal fue que, frente a millones de canadienses y en vivo, no supo cómo reaccionar, pues en lugar de ofrecer una respuesta serena, rápida y contundente se mostró visiblemente molesto y muy incómodo ante los señalamientos del líder neodemócrata, quien, por cierto, nunca perdería el tono suave pero firme en sus acusaciones directas en contra de Ignatieff. Desde ese momento, la vehemencia en el discurso del líder liberal menguó en beneficio directo de Jack Layton, quien tomaría la iniciativa durante la segunda parte del debate en inglés.

Las consecuencias del debate y la actitud impotente de Ignatieff se evidenciaron al día siguiente, pues varias casas encuestadoras mostraban una caída liberal abrupta, frente a un incremento insólito neodemócrata, que por primera vez en la historia se posicionaba por encima del Partido Liberal. Ante esta situación y previniendo el catastrófico resultado para su causa, Ignatieff optó entonces por hacer a un lado las críticas en contra del gobierno conservador en la parte final de la campaña, para concentrarse en la figura de Jack Layton, en un claro intento de, por lo menos, no perder la primera minoría en el Parlamento.

Esta última estrategia de Ignatieff durante las dos semanas finales fue quizá el elemento que terminó por inclinar la balanza en favor del Partido Neodemócrata, pues con esa actitud el líder liberal manifestaba su resignación y lo inevitable de su derrota.

Ante esta dinámica (véase el cuadro 3), las elecciones del 2 de mayo de 2011 arrojaron una serie de resultados históricos en varios niveles: primero, la obtención de 
un gobierno de mayoría para el renovado Partido Conservador con ciento sesenta y siete escaños (el primero desde su refundación en 2003); segundo, el ascenso -por primera vez en la historia- del Partido Neodemócrata como primera minoría con ciento dos diputados, que colocaba a la izquierda canadiense ante la posibilidad de enfrentar directamente, en el Parlamento, las propuestas y decisiones de la derecha en el poder. Y tercero, los resultados de 2011, que relegarían al Partido Liberal como la tercera fuerza política -quizá por primera vez en la historia-, al obtener tan sólo treinta y cuatro curules. Al mismo tiempo, el Bloque Quebequense quedaría reducido a su mínima expresión, con cuatro miembros del Parlamento, en tanto que el Partido Verde, pese a la exclusión de su lideresa Elizabeth May de los debates televisivos, fue capaz de obtener un asiento en el Parlamento canadiense por primera vez.

De esta manera, todos y cada uno de los partidos representados en la Cámara de los Comunes tendrían sus razones para recordar las elecciones federales de 2011, ya sea como un antes o un después en sus distintas historias políticas.

\begin{tabular}{|c|c|c|c|c|}
\hline \multicolumn{5}{|c|}{$\begin{array}{c}\text { Cuadro } 3 \\
\text { ELECCIONES FEDERALES, } 2 \text { DE MAYO DE } 2011\end{array}$} \\
\hline Partido & $\begin{array}{c}\text { Diputados } \\
\text { (Cámara de } \\
\text { los Comunes) }\end{array}$ & $\begin{array}{l}\text { Porcentaje } \\
\text { de escaños }\end{array}$ & Votos válidos & $\begin{array}{c}\text { Porcentaje } \\
\text { de votos }\end{array}$ \\
\hline Partido Conservador & 166 & 53.9 & 5835270 & 39.6 \\
\hline Partido Neodemócrata & 103 & 33.4 & 4512411 & 30.6 \\
\hline Partido Liberal & 34 & 11 & 2783076 & 18.9 \\
\hline Bloque Quebequense & 4 & 1.3 & 891425 & 6 \\
\hline Partido Verde & 1 & 0.3 & 572095 & 3.9 \\
\hline Otros & - & - & 129703 & 1 \\
\hline Total & 308 & 99.9 & 14723980 & 100 \\
\hline
\end{tabular}

Cabe agregar que, una vez confirmados los resultados del 2 de mayo, así como la nueva composición en la Cámara de los Comunes (véase el cuadro 4), los líderes del Partido Liberal, Michael Ignatieff, y del Bloque Quebequense, Gilles Duceppe, presentaron sus respectivas renuncias. Ambos casos destacan por el hecho de que los dos líderes perdieron incluso sus escaños durante este proceso electoral. En el caso de Ignatieff, fue derrotado en su circunscripción de Etobibicoke-Lakeshore, Ontario, 
por el conservador Bernard Trottier, mientras que Gilles Duceppe fue vencido en la circunscripción de Laurier-Saint-Marie, Quebec, por su contrincante neodemócrata, Héléne Laverdiére.

\begin{tabular}{|c|c|c|c|c|c|c|}
\hline \multicolumn{7}{|c|}{$\begin{array}{c}\text { Cuadro } 4 \\
\text { COMPOSICIÓN DE LA CÁMARA DE LOS COMUNES POR PARTIDO POLÍTICO } \\
\text { Y POR REGIÓN, DESPUÉS DE LAS ELECCIONES FEDERALES DEL } 2 \text { DE MAYO } \\
\text { DE } 2011\end{array}$} \\
\hline Región & $\begin{array}{c}\text { Partido } \\
\text { Conservador }\end{array}$ & $\begin{array}{l}\text { Partido } \\
\text { Liberal }\end{array}$ & $\begin{array}{c}\text { Partido } \\
\text { Neodemócrata }\end{array}$ & $\begin{array}{c}\text { Bloque } \\
\text { Quebequense }\end{array}$ & $\begin{array}{l}\text { Partido } \\
\text { Verde }\end{array}$ & $\begin{array}{c}\text { Total } \\
\text { por región }\end{array}$ \\
\hline $\begin{array}{l}\text { Columbia } \\
\text { Británica }\end{array}$ & 21 & 2 & 12 & - & 1 & 36 \\
\hline Alberta & 27 & - & 1 & - & - & 28 \\
\hline $\begin{array}{l}\text { Provincias } \\
\text { de las Praderas }\end{array}$ & 24 & 2 & 2 & - & - & 28 \\
\hline Ontario & 73 & 11 & 22 & - & - & 106 \\
\hline Quebec & 5 & 7 & 59 & 4 & - & 75 \\
\hline $\begin{array}{l}\text { Provincias } \\
\text { del Atlántico }\end{array}$ & 14 & 12 & 6 & - & - & 32 \\
\hline $\begin{array}{l}\text { Territorios } \\
\text { del Norte }\end{array}$ & 2 & - & 1 & - & - & 3 \\
\hline Total por partido & 166 & 34 & 103 & 4 & 1 & 308 \\
\hline
\end{tabular}

\section{Conclusiones}

Una vez revisado el complejo escenario político de Canadá durante los últimos once años, resulta más clara la idea de que en el país de la hoja de maple ha habido una serie de hechos cuyos orígenes e impactos han provocado profundos reacomodos entre las fuerzas políticas del país, representadas dentro de la Cámara de los Comunes, que, dicho sea de paso, opera como el eje central de la maquinaria política canadiense, al emanar de ahí precisamente, como líder del partido mayoritario, el primer ministro y sus ministros de Estado.

En este sentido, a raíz de una serie de estrategias políticas, mediáticas y electorales, las distintas organizaciones partidistas representativas en Canadá han sido las constructoras de su propio destino, al ganar o ceder espacios como resultado de sus decisiones. Como ejemplo sobresale la profunda descomposición del Partido Liberal, que si bien tiene sus orígenes en añejas disputas intrínsecas, lo cierto es que las pugnas 
y el relevo adelantado de Jean Chrétien, provocado por Paul Martin y sus seguidores en 2003, condujeron a los liberales a una espiral descendente que no ha cesado, al menos hasta el más reciente proceso electoral en mayo de 2011. Aunado a lo anterior, la falta de unidad interna en torno a sus liderazgos posteriores, así como las contradicciones y la toma de decisiones copulares han terminado por alejar a sus votantes tradicionales, dejando a la deriva al que otrora era la opción natural de gobierno para Canadá.

Cabe subrayar que esta gradual caída de la fracción liberal se ha conjugado con la llegada de un liderazgo extremadamente efectivo dentro del bando conservador en la persona de Stephen Harper, quien no sólo ha podido reunificar a la fragmentada derecha del país, sino que a través de la refundación del Partido Conservador, en 2003, aglutinó a su alrededor los viejos valores políticos tories de las metrópolis, al lado de las tradiciones más conservadoras y evangélicas del oeste rural. Sobre esto mismo, llama la atención cómo Harper consolidó en tan poco tiempo a su partido como gobierno de mayoría, al menos hasta las elecciones federales programadas para el 2015. De esta forma, la opción conservadora canadiense tiene ante sí la oportunidad de generar una serie de cambios políticos estructurales, extensivos incluso a su propia sociedad.

No obstante, ha de subrayarse que el gobierno tory tiene frente a sí el reto de enfrentar candentes debates parlamentarios con el Partido Neodemócrata, cuyo ascenso, como observamos a lo largo de este trabajo, está en proporción directa a la declinación de la fracción liberal y del Bloque Quebequense. Este incremento del partido, representante de la izquierda sindical y de los trabajadores canadienses, obedeció en buena medida a la adecuada gestión y liderazgo de Jack Layton, quien, gracias a un discurso coherente y firme, posicionó a sus correligionarios como la primera minoría en las elecciones de 2011. Sin embargo, su muerte a causa del cáncer, en agosto de ese mismo año, colocó a los neodemócratas ante un escenario con dos frentes: por un lado, tendrían que fungir como una oposición firme versus un gobierno conservador abiertamente de derecha; y por el otro, tendrían que ofrecer una imagen de unidad y madurez política durante su proceso interno para elegir un nuevo liderazgo. Este proceso culminó el 24 de marzo de 2012 con la elección de Thomas Mulcair como su nueva cabeza y líder. Así, una vez confirmado el liderazgo de Mulcair, quien funge además como líder de la oposición en la Cámara de los Comunes, comenzaron a revelarse con intensidad las discrepancias entre el gobierno tory de derecha y la oposición neodemócrata -en teoría- de izquierda, toda vez que ambas agendas no han compartido históricamente ni forma ni fondo en temas relativos a seguridad, educación, salud, reformas migratorias, entre otros asuntos.

Si partimos de la consideración de que la derecha y la izquierda se enfrentarán en el Parlamento canadiense en los próximos años, es de esperarse una posible polarización entre ambos grupos políticos encabezados por Harper y Mulcair, cuya naturaleza 
divergente corre el riesgo no sólo de polarizar los debates parlamentarios, sino también la posición y opinión de los ciudadanos en todo el país.

Para expresar esta polarización en Canadá, es oportuno concluir este artículo con una cita del académico y politólogo canadiense Stephen Clarkson, quien afirma que "El peligro de las posturas de Harper no es la polarización de la política canadiense, la cual ya ha sido dividida entre la izquierda y la derecha antes. Las cosas van más allá porque él [Harper] amenaza con alterar el patrimonio constitucional del país" (Clarkson, 2012).

Para finalizar, sólo resta agregar que más allá de las filias o fobias que despiertan los partidos Conservador o Neodemócrata, lo cierto es que la política canadiense se encontrará, por primera vez en su historia, ante dos posiciones claras que contrastarán dos visiones diferentes para encarar los problemas nacionales. Ello ocurrirá al mismo tiempo frente a la obligada reestructuración interna del Partido Liberal, cuya mínima representación no alcanzará ni siquiera para lograr acuerdos significativos con los neodemócratas.

Así pues, la composición de la XLI Legislatura canadiense pondrá a prueba la capacidad de adaptación de un sistema político vetusto que ha de cumplir con las nuevas demandas democráticas de una sociedad moderna y en constante movimiento.

\section{Biblografía}

ANDRÉ BLAIs et al.

2004 "Do (Some) Canadian Voters Punish a Prime Minister for Calling a Snap Election?", Political Studies, vol. 52, pp. 307-323.

BBC NEWS

2011 "Canadian Government Falls Alter No-confidence Vote", en <http: / www. bbc.co.uk/news / world-us-canada-12865339>, consultada el 18 de abril 2012.

\section{Blaze Carlson, Kathrin}

2011 "Ipsographic: The Unpredictible Nature of Elections Campaigns", en $<$ http: / / news.nationalpost.com/ photo_gallery/infographic-the-unpredictable-nature-of-election-campaigns / >, consultada el 13 de marzo de 2012.

C-SPAN Video LiBRARY

2006 "Canadian Party Leaders Debate, Jan 9, 2006", en <http: / / www.c-spanvideo. org/program/190614-1>, consultada el 11 de mayo de 2012. 


\section{CANADA.COM}

2012 "Government Signals Lack of Commitment to F-35 Purchase", en <http:/ / www.canada.com/technology / Government+signals+lack+commitment+p urchase / 6392080/ story.html>, consultada el 18 de abril de 2012.

2008 "Liberals, NDP Release Multi-Billion Plans to Create Childcare Spots", en <http: / / www.canada.com/ ottawacitizen / news / story.html?id=ea42160bd8d8-4b82-835c-c73db11d52ab>, consultada el 18 de abril de 2012.

\section{CBC Digital Archives}

2008 "Prime Ministers Address the Nation: Stephen Harper Addresses Political Turmoil", en <http:/ / www.cbc.ca/video/\# /News/Digital_Archives/Politics/Federal_Politics /1399596553/ID=1853476230>, consultada el 11 de mayo de 2012.

CBC NEWS

2008 “Liberals, NDP, Bloc Sign Deal on Proposed Coalition", en <http: / www.cbc. $\mathrm{ca} /$ news / canada/story/2008/12/01/coalition-talks.html>, consultada $11 \mathrm{de}$ mayo de 2012.

2007 “The Income Trust Probe: FAQ's", en < http: / / www.cbc.ca/ news/ background/ personalfinance/incometrust-probe-faqs.html>, consultada el 3 de abril de 2012.

2006 "Indepth. The 38th Parliament, June 28, 2004-Nov. 29, 2005", en <http:// www.cbc.ca/news/background/parliament38/index.html>, consultada el 29 de marzo de 2011.

2004 "Slim Majority Oppose Missile Defense: Poll", en <http://www.cbc.ca/ news / canada/story/2004/11/04/poll_missile041104.html>, consultada el 23 de marzo de 2012.

\section{Clarkson, Stephen}

2012 "Has the Centre Vanished? The Past and Future of the Middle Ground in Canadian Politics", The Literary Review of Canada, en <http:/ / reviewcanada.ca/essays / 2011/10/01 / has-the-centre-vanished/> , consultada el 19 de abril de 2012.

2005 The Big Red Machine. How the Liberal Party Dominates Canadian Politics, Vancouver, University of British Columbia Press.

Comision of Inquiry into the Sponsorship Program and Advertising Activities

2005 "Who Is Responsible? Phase 1 Report", en <http: / / epe.lac-bac.gc.ca/100/ 206/301 / pco-bcp / commissions / sponsorship-ef/06-02-10/ www.gomery. ca/en/phase1report/ default.htm>, consultada el 23 de marzo de 2012. 
CTV.CA

2011 "Tory Focus on Jets and Jails Threatening to Bankrupt Canada Ignatieff Says", en <http: / / calgary.ctv.ca/servlet/an/local/CTVNews / 20110328/wpg_election_ jets_110328/20110328/The\%20Mentalist>, consultada el 25 de octubre de 2011.

2005 "Chrétien Plays Hard Ball in Inquiri Testimony", en <http: / www.ctv.ca/ generic/WebSpecials/sponsorship_scandal/chretien.html>, consultada el 23 de marzo de 2012.

CTV NEWS

2011 "Harper Gov't 'Low-balling' Price of F-35: Ignatieff", en <http: / / www.ctv. ca / CTVNews / Canada / 20110310 / jets-report-speakers-rulings-110310/>, consultada el 22 de octubre de 2011.

2009 "Liberals Officially Name Ignatieff Party Leader", en <http: / www.ctv.ca/ CTVNews / Canada/20090502/liberal_convention_090502/>, consultada el 11 de mayo de 2012.

Dornan, Christ y John H. PAmmett

2004 The Canadian General Election 2004, Toronto, Dundun Press.

FlanAGAN, TOM

2009a Harper's Team. Behind the Scenes in the Conservative Rise to Power, Montreal, McGill-Queen's University Press.

2009b Waiting for the Wave. The Reform Party and the Conservative Movement, Montreal, McGill-Queen's University Press.

JEFFREY, BROKE

2010 Divided Royalties. The Liberal Party of Canada, 1984-2008, Toronto, University of Toronto Press.

KILPATRICK, SHILL

2008 "Liberals, NDP Firm Up Deal to Topple Tories", The Globe and Mail, 1 de diciembre, en <http: / / portal.sre.gob.mx/ canada/pdf/liberalsdd1.pdf >, consultada el 11 de mayo de 2012.

Liberal PARTY

2011 "Liberals Oppose Bill S-10 as Conservatives Hide Mounting Prison Costs", en <http://www.liberal.ca/newsroom/news-release/liberals-oppose-bills10-conservatives-hide-mounting-prison-costs $/>$, consultada el 21 de octubre. 


\section{LJUNGGREN DAVID}

2009 “Canada's Government Survives No-Confidence Motion", en <http:// ca.reuters.com/article/domesticNews/idCATRE58T4BE20091001?pageNumber $=2 \&$ virtualBrandChannel=0>, consultada el 14 de septiembre de 2011.

\section{MACLEANS.CA}

2011 "We Will Choose between Stable National Government and Reckelss Coalition", Beyond the Commons, en <http: / / www2.macleans.ca/2011/03/26/ we-willchoose-between-stable-national-government-and-a-reckless-coalition $/>$, consultada el 24 de febrero de 2012.

\section{Marzolini, Michael}

1997 "The Regionalization of Canadian Electoral Politics", en Alan Stewart Frizzell y John H. Pammett, eds., Canadian General Election 1997, Toronto, Dundurn Press.

MiLKe, MARK

2011 “Jack Layton's Legacy: More History, Less Hagiography Please”, C2C Journal, vol. 5 , no. 3 , otoño.

NAMAKForoOsh, MoHAmmad NAGHI

2005 Metodología de la investigación, México, Limusa Noriega.

Now Public Crowd Powered Media

2008 “Green Shift-Jack Layton: Dion Carbon Tax vs. Cap and Trade", en <http:/ / www.nowpublic.com/ environment/green-shift-jack-layton-dion-carbontax-vs-cap-and-trade>, consultada el 17 de abril de 2012.

\section{PARLIAMENT OF CANADA}

2011a "Electoral Results by Party", en <http:/ / www.parl.gc.ca/parlinfo/compilations / electionsandridings/ResultsParty.aspx $>$, consultada el 2 de febrero de 2012.

2011b "Liberal Party of Canada. Leadership Conventions", en <http: / www.parl. gc.ca / ParlInfo / Files / Party.aspx?Item=b82f0db7-8535-4cc0-8bad-fd3ad8ea3 d49\&Section=LeadershipConvention $>$, consultada el 9 de abril de 2012.

2010 "Memorandum of Understanding", en <http: / / es.scribd.com/ doc/33140175/ 100615-Mou-en-Final>, consultada el 9 de febrero de 2012. 
Pugliese, DAVID

2011 "Will F-35s Include Engines?", Winnipeg Free Press, en <http://www.winnipegfreepress.com / canada/ will-f-35s-include-engines-119997399. html?device $=$ mobile $>$, consultada el 22 de octubre de 2011 .

Simon Fraser University, Political Science Department

2012 "Elections, Canadian Elections Pollster's Success", en <http://www.sfu. ca/ aheard/elections/ poll-results.html>, consultada el 15 de marzo de 2012.

2008 "Elections, Canadian Elections Pollster's Success", en <http:/ /www.sfu. ca/ aheard/elections / poll-results.html>, consultada el 15 de marzo de 2012.

2004a "Elections, Canadian Elections Pollster's Success", en <http://www.sfu. ca/ aheard/elections / poll-results.html>, consultada el 15 de marzo de 2012.

2004b “2004 Canadian Elections Results", en <http://www.sfu.ca/ aheard/ elections / 2004-results.html>, consultada el 17 de mayo de 2012.

TABER, JANE

2010 "Michael Ignatieff Faces Caucus Rift over Afghan Extension", The Globe and Mail, en <http:/ / www.theglobeandmail.com/news/politics / ottawa-notebook / michael-ignatieff-faces-caucus-rift-over-afghan-extension/article 1803052 / > , consultada el 11 de mayo de 2012.

\section{Three Hundred Eight.com}

2011 "Average of All Polls Released Each Month Canada (January 2009-December 2011)", en <http://4.bp.blogspot.com/-IBweNJG84IU/TxWKt4dqOWI/ AAAAAAAAG7U / sltKezGEN-0/s1600/Monthly+Federal+Polls.PNG>, consultada el 11 de mayo de 2012.

2006 "Past Elections Results (2006)", en <http://threehundredeight.blogspot. $\mathrm{mx} / 2008 / 12$ / past-election-results.html>, consultada el 6 de abril de 2012 .

\section{Toronto NeWs}

2007 “The Star.com, Harper Letter Called Kioto Socialist Scheme”, en <http:/ / www.thestar.com/News / article/176382>, consultada el 19 de enero de 2012.

WinsOR, Hugh

2009 "How the Polls Affected Voters", The Globe and Mail, en <http: / m.theglobeandmail.com / news / politics / article717152.ece? service=mobile $>$, consultada el 22 de marzo de 2012. 
You TuBE

2011 “2011 Federal Leaders Debate (Full HD Video)”, en <http: / / www.youtube. com / watch?v=jGYE2d4LJ5M\&feature $=$ relmfu $>$, consultada el 25 de abril de 2012.

2008 "Canadian Leadership Debate 2008", en <http: / www.youtube.com / watch? $\mathrm{v}=\mathrm{nM0wCFpPd5g}>$, consultada el 11 de mayo de 2012. 
